\title{
An in vitro study evaluating the effect of ferrule design on the fracture resistance of endodontically treated mandibular premolars after simulated crown lengthening or forced eruption methods
}

Qingfei Meng ${ }^{1,2}$, Qian Ma ${ }^{2 *}$, Tianda Wang ${ }^{2}$ and Yaming Chen ${ }^{2}$

\begin{abstract}
Background: The purpose of this study was to evaluate the effect of ferrule design on the fracture resistance of endodontically treated mandibular first premolars after simulated crown lengthening and orthodontic forced eruption methods restored with a fiber post-and-core system.

Methods: Forty extracted and endodontically treated mandibular first premolars were decoronated to create lingualto-buccal oblique residual root models, with a $2.0 \mathrm{~mm}$ height of the lingual dentine wall coronal to the cementoenamel junction, and the height of buccal surface at the cemento-enamel junction. The roots were divided randomly into five equal groups. The control group had undergone incomplete ferrule preparation in the cervical root, with 0. $0 \mathrm{~mm}$ buccal and $2.0 \mathrm{~mm}$ lingual ferrule lengths (Group F0). Simulated surgical crown lengthening method provided ferrule preparation of $1.0 \mathrm{~mm}$ (Group CL/F1) and $2.0 \mathrm{~mm}$ (Group CL/F2) on the buccal surface, with ferrule lengths of 3 . $0 \mathrm{~mm}$ and $4.0 \mathrm{~mm}$ on the lingual surface, respectively. Simulated orthodontic forced eruption method provided ferrule preparation of $1.0 \mathrm{~mm}$ (Group OE/F1) and $2.0 \mathrm{~mm}$ (Group OE/F2) on the buccal surface and ferrule lengths of $3.0 \mathrm{~mm}$ and $4.0 \mathrm{~mm}$ on the lingual surface, respectively. After restoration with a glass fiber post-and-core system and a cast Co$\mathrm{Cr}$ alloy crown, each specimen was embedded in an acrylic resin block to a height on the root $2.0 \mathrm{~mm}$ from the apical surface of the crown margin and loaded to fracture at a $135^{\circ}$ angle to its long axis in a universal testing machine. Data were analyzed statistically using two-way ANOVA with Tukey HSD tests and Fisher's test, with $a=0.05$.
\end{abstract}

Results: Mean fracture loads (kN) for groups FO, CL/F1, CL/F2, OE/F1 and OE/F2 were as follows: 1.01 (S.D. = 0.26), 0.91 (0.29), 0.73 (0.19), $0.96(0.25)$ and $0.76(0.20)$, respectively. Two-way ANOVA revealed significant differences for the effect of ferrule lengths $(P=0.012)$ but no differences for the effect of cervical treatment methods $(P=0.699)$. The teeth with no buccal ferrule preparation in control group F0 had the highest fracture resistance. In contrast, the mean fracture loads for group CL/F2 with a 2.0-mm buccal and 4.0-mm lingual ferrule created by simulated crown lengthening method were lowest $(P=0.036)$.

Conclusions: Increased apically complete ferrule preparation resulted in decreased fracture resistance of endodontically treated mandibular first premolars, regardless of whether surgical crown lengthening or orthodontic forced eruption methods been used.

Keywords: Ferrule, Surgical crown lengthening, Orthodontic forced eruption, Fracture resistance, Residual root

\footnotetext{
* Correspondence: qianma1981@126.com

${ }^{2}$ College of Stomatology, Nanjing Medical University, 136 Hanzhong Road,

Nanjing 210029, Jiangsu Province, China

Full list of author information is available at the end of the article
}

(c) The Author(s). 2018 Open Access This article is distributed under the terms of the Creative Commons Attribution 4.0 International License (http://creativecommons.org/licenses/by/4.0/), which permits unrestricted use, distribution, and reproduction in any medium, provided you give appropriate credit to the original author(s) and the source, provide a link to the Creative Commons license, and indicate if changes were made. The Creative Commons Public Domain Dedication waiver (http://creativecommons.org/publicdomain/zero/1.0/) applies to the data made available in this article, unless otherwise stated. 


\section{Background}

When endodontically treated teeth are restored with a post-and-core system, the prognosis can be affected by the following factors: the remaining amount of residual tooth [1-4], ferrule design $[3,5-8]$, post material $[3,5,6]$, the tooth fracture mode and its severity $[9,10]$, and so on. According to previous studies [1-4], the amount of residual tooth structure has been considered the most important factor with regard to the fracture resistance of endodontically treated teeth. If adequate supragingival tooth structure could be conserved and greater than a $1.0-\mathrm{mm}$ complete ferrule could be achieved, the fracture resistance would increase significantly and the long-term success of post-and-core restorations could be expected [7, 8].

However, because of severe dental caries, wedgeshaped defects, trauma or other reasons, teeth were broken obliquely in some cases, starting at the crown and extending longitudinally through the pulp chamber to the cervical line or subgingival area, with one or more dentine walls lost and only an incomplete ferrule prepared in the residual cervical root. Mangold et al. had evaluated the fracture resistance of endodonticallytreated residual teeth in this particular condition and found that the fracture loads of such obliquely broken teeth decreased proportionally with the loss of dentine walls [11-13]. Moreover, the position of the lost dentine wall would still affect the long-term success of oblique endodontic root restorations [14, 15]. According to previous studies $[14,15]$, the fracture resistance of anterior upper teeth having a $2.0-\mathrm{mm}$ lingual ferrule (labial dentine wall was lost) was better than those with a 2.0$\mathrm{mm}$ labial ferrule (lingual dentine wall was lost). The lowest fracture resistance was found in residual roots with no ferrule or only a labial ferrule. The long-term prognosis for such residual roots appears to be poor after post-and-core restorations.

The surgical crown lengthening method (SCLM) and orthodontic forced eruption method (OFEM) have been recommended for restoring subgingival roots [16-20]. SCLM reestablishes the dentogingival junction at a more apical level on the root to accommodate the junctional epithelium and the connective tissue attachment in a relatively short time frame [16-18]. In contrast, continued, slow, passive or active OFEM at approximately $2 \mathrm{~mm}$ per month allows the periodontal ligament to repair and the alveolar bone to remodel by orthodontic adjustments $[19,20]$. Both cervical treatment methods can provide sound tooth structure over the bone crest for the complete ferrule preparation. OFEM has been shown to provide greater fracture resistance and better clinical outcome for post-and-core restored roots than SCLM [4, 8]. However, whether SCLM or OFEM is supportive for residual roots with an oblique fracture is still unclear.
The purpose of this in vitro study was to investigate the effect of ferrule length on the fracture resistance of obliquely-fractured (with buccal tooth structure lost) endodontically treated mandibular premolars, which were treated with simulated SCLM or OFEM to provide a complete ferrule and restored with a prefabricated fiber post and core system. The null hypotheses were that the fracture resistance of endodontically-treated residual roots would not be affected by the ferrule length, nor by the cervical treatment methods (SCLM or OFEM).

\section{Methods}

\section{Specimen preparation}

Forty healthy human mandibular first premolars recentlyextracted for orthodontic reasons from patients aged 2030 years who lived in the same locality without water fluoridation were used for this study. Written informed consent was obtained under a protocol approved by the Ethics Committee of Affiliated Stomatology Hospital of Nanjing Medical University. After cleaning and the removal of attached soft tissues, the teeth were examined stereoscopically at $10 \times$ magnification to exclude those already cracked before being stored in $0.9 \%$ saline solution at $4{ }^{\circ} \mathrm{C}$ for no longer than 2 weeks [8]. Diamond disks were used to section the natural crowns transversely, $2 \mathrm{~mm}$ occlusal to the buccal cemento-enamel junction (CEJ) with an average root length of $15.0 \pm 1.0 \mathrm{~mm}$ to simulate endodontically treated roots (Fig. 1). All the roots were assigned randomly into five equal groups (F0, CL/F1, $\mathrm{CL} / \mathrm{F} 2, \mathrm{OE} / \mathrm{F} 1$ and $\mathrm{OE} / \mathrm{F} 2)$, according to a table of random numbers. The root dimensions including the root lengths, the cross-sectional widths of the canal walls at the mesial, buccal, distal and lingual root face sites and the mesiodistal and buccolingual diameters of the roots were measured to $0.02 \mathrm{~mm}$ with a vernier caliper (Vernier Caliper Model 93,218-0654, Harbin Measuring \& Cutting Tool Group Co. Ltd., Harbin, PR China). The roots had similar dimensions among the five groups, as shown in Table 1.

The root canals were prepared with hand files (Kfiles, Dentsply-Maillefer, Ballaigues, Switzerland) and

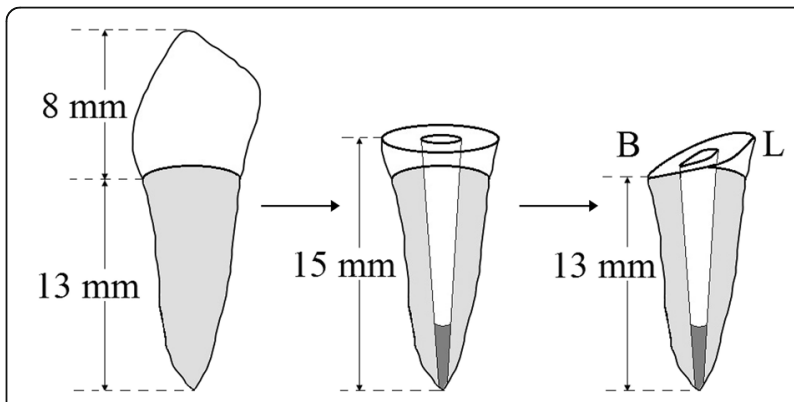

Fig. 1 Process of lingual-to-buccal oblique residual root preparation. $B$ : buccal surface of root; L: lingual surface of root 
Table 1 Mean dimensions ( $\mathrm{mm}$ ) of randomly assigned mandibular first premolar roots in each group

\begin{tabular}{|c|c|c|c|c|c|c|c|}
\hline \multirow{2}{*}{$\begin{array}{l}\text { Group } \\
(N=40)\end{array}$} & \multirow{2}{*}{$\begin{array}{l}\text { Root } \\
\text { Length }^{a}\end{array}$} & \multicolumn{6}{|c|}{ Width of canal wall sites, and roots, at root face ${ }^{a}$} \\
\hline & & Mesial & Buccal & Distal & Lingual & $M-D$ & $B-L$ \\
\hline F0 & $15.12(0.36)$ & $2.19(0.30)$ & $2.55(0.15)$ & $2.17(0.41)$ & $2.36(0.26)$ & $6.18(0.97)$ & $8.16(0.73)$ \\
\hline $\mathrm{CL} / \mathrm{F} 1$ & $15.16(0.35)$ & $2.04(0.41)$ & $2.40(0.43)$ & $1.92(0.19)$ & $2.43(0.20)$ & $5.66(0.58)$ & $7.88(0.63)$ \\
\hline $\mathrm{CL} / \mathrm{F} 2$ & $15.18(0.27)$ & $2.47(0.54)$ & $2.63(0.37)$ & $2.12(0.33)$ & $2.60(0.34)$ & $6.40(0.77)$ & $8.25(0.52)$ \\
\hline $\mathrm{OE} / \mathrm{F} 1$ & $15.12(0.26)$ & $2.06(0.37)$ & $2.47(0.27)$ & $2.00(0.42)$ & $2.52(0.38)$ & $5.89(0.96)$ & $8.07(0.70)$ \\
\hline OE/F2 & $15.19(0.42)$ & $2.18(0.30)$ & $2.65(0.30)$ & $2.11(0.33)$ & $2.66(0.36)$ & $6.26(0.60)$ & $8.13(0.35)$ \\
\hline 1-way ANOVA & $\begin{array}{l}F=0.083 \\
P=0.987\end{array}$ & $\begin{array}{l}F=1.502 \\
P=0.223\end{array}$ & $\begin{array}{l}F=0.823 \\
P=0.519\end{array}$ & $\begin{array}{l}F=0.691 \\
P=0.603\end{array}$ & $\begin{array}{l}F=1.2 \\
P=0.328\end{array}$ & $\begin{array}{l}F=1.140 \\
P=0.354\end{array}$ & $\begin{array}{l}F=0.412 \\
P=0.799\end{array}$ \\
\hline
\end{tabular}

Group F0: glass fiber post-core with $0.0 \mathrm{~mm}$ buccal and $2.0 \mathrm{~mm}$ lingual ferrule lengths, as control; Group CL/F1: glass fiber post-core with simulated crown lengthening and $1.0 \mathrm{~mm}$ buccal and $3.0 \mathrm{~mm}$ lingual ferrule lengths; Group CL/F2: glass fiber post-core with simulated crown lengthening and $2.0 \mathrm{~mm}$ buccal and $4.0 \mathrm{~mm}$ lingual ferrule lengths; Group OE/F1: glass fiber post-core with simulated orthodontic forced tooth eruption and $1.0 \mathrm{~mm}$ buccal and $3.0 \mathrm{~mm}$ lingual ferrule lengths; Group OE/ F2: glass fiber post-core with simulated orthodontic forced tooth eruption and $2.0 \mathrm{~mm}$ buccal and $4.0 \mathrm{~mm}$ lingual ferrule lengths

${ }^{a}$ Mean (Standard Deviation); M-D: mesiodistal root width; B-L: buccolingual root width

size 4 Gates-Glidden drills (Dentsply-Maillefer) for the purpose of standardized canal forms [8], rinsed with 2. $5 \%$ sodium hypochlorite solution, dried with paper points, and then applied with a thin layer of sealer (AH Plus, Dentsply Detrey, Konstanz, Germany). The cold laterally-condensed gutta percha points (Dentsply International Inc., York, PA, USA) were placed to obturate the canals. After endodontic treatment, all the residual roots were cut as lingual-to-buccal obliquelybroken root models, starting at the middle point of the lingual section and extending longitudinally to the middle point of the buccal CEJ, with the height of buccal dentine wall $2.0 \mathrm{~mm}$ lower than that of the lingual position in the section area (Fig. 1). Each root was restored with prefabricated glass fiber post-and-core system. Post space was prepared to $10 \mathrm{~mm}$ deep for No. 2 glass fiber post (\#2, R.T.D., France), using matching drills with a slow speed contra angle handpiece, according to the manufacturer's instructions. The prepared root wall was first etched with $32 \%$ phosphoric acid gel (UNIETCH, BISCO, Inc., Schaumburg, IL, USA) for $15 \mathrm{~s}$ and then rinsed thoroughly with an air-water spray and dried lightly with paper points. A resin-based adhesive (ONE-STEP PLUS, BISCO, Inc) was applied twice as a thin layer over the walls of the root wall and once over the surfaces of a prefabricated glass fiber post. After thinning lightly with dry oil-free air, the adhesive was light-cured for $10 \mathrm{~s}$ at $600 \mathrm{~mW} / \mathrm{cm}^{2}$ (Variable Intensity Polymerizer Junior, BISCO, Inc). The post-hole was filled completely by injecting resin luting cement (DUAL-LINK luting cement, BISCO, Inc) into which the fiber post was inserted. This was followed by lightcuring for $40 \mathrm{~s}$ from a coronal direction. A resin composited core (Light-Core ${ }^{\text {Tx }}$, Bisco, Inc) was built up around the post and light-cured again for $40 \mathrm{~s}$.

Cores, $6.0-8.0 \mathrm{~mm}$ high with a $6^{\circ}$ convergence angle, were prepared using a milling machine (F3/Egro, Degussa AG, Dusseldorf, Germany) with flat-ended tapered carbide burs, leaving a $0.8 \mathrm{~mm}$ wide encircling shoulder in dentine. The incomplete ferrule was designed with no ferrule on the buccal surface and $2.0 \mathrm{~mm}$-high ferrule on the lingual surface in the control group (Group F0), which had a $6.0 \mathrm{~mm}$ high core. Simulated SCLM resulted in nonuniform circumferential ferrule preparation of $1.0 \mathrm{~mm}$ length (Group CL/F1) and of $2.0 \mathrm{~mm}$ length (Group CL/ F2) in the buccal surface, with the ferrule prepared 3.0 and $4.0 \mathrm{~mm}$ length respectively in the lingual surface of the oblique residual roots, which increased the height of the core to $7.0 \mathrm{~mm}$ and $8.0 \mathrm{~mm}$, respectively. Simulated OFEM resulted in complete ferrule preparation of $1.0 \mathrm{~mm}$ (Group OE/F1) and $2.0 \mathrm{~mm}$ (Group OE/F2) on the buccal surface, with the ferrule length at 3.0 and $4.0 \mathrm{~mm}$, respectively, on the lingual surface, while maintaining the $6.0 \mathrm{~mm}$ height of the core (as shown in Fig. 2).

After $24 \mathrm{~h}$ in the isotonic saline storage medium, a standardized Cobalt-Chromium (Co-Cr) alloy (BEGO Bremer Goldschlägerei Wilh. Herbst GmbH \& Co. KG, Germany) crown fabricated in the dental laboratory for each of the prepared teeth was cemented with glassionomer cement (Glasionomer, Shofu Inc., Kyoto, Japan). The teeth were kept in the storage medium at all time except during experimental testing.

Each root was coated with a $0.1-0.2 \mathrm{~mm}$ thin vinyl polysiloxane silicone layer (modulus of elasticity 0 . $3 \mathrm{MPa}$ ) (Aquasil, Dentsply International Inc) to simulate the periodontal ligament before being embedded, from $2.0 \mathrm{~mm}$ apical to the crown preparation margins, in a block of self-cured acrylic resin (Shanghai Dental Materials Manufacture Co., Shanghai, PR China) (Fig. 3).

\section{Fatigue resistance testing}

A 1,200,000-times dynamic load of 0-50 N, which simulated the oral masticating condition, was applied to the buccal cusp of the Co-Cr alloy crown, at an angle of $135^{\circ}$ from the long axis of the root, using a cylindrical $\mathrm{Ni}-\mathrm{Cr}$ alloy rod $(4.0 \mathrm{~cm}$ long $\times 1.2 \mathrm{~cm}$ diameter $)$ in a 

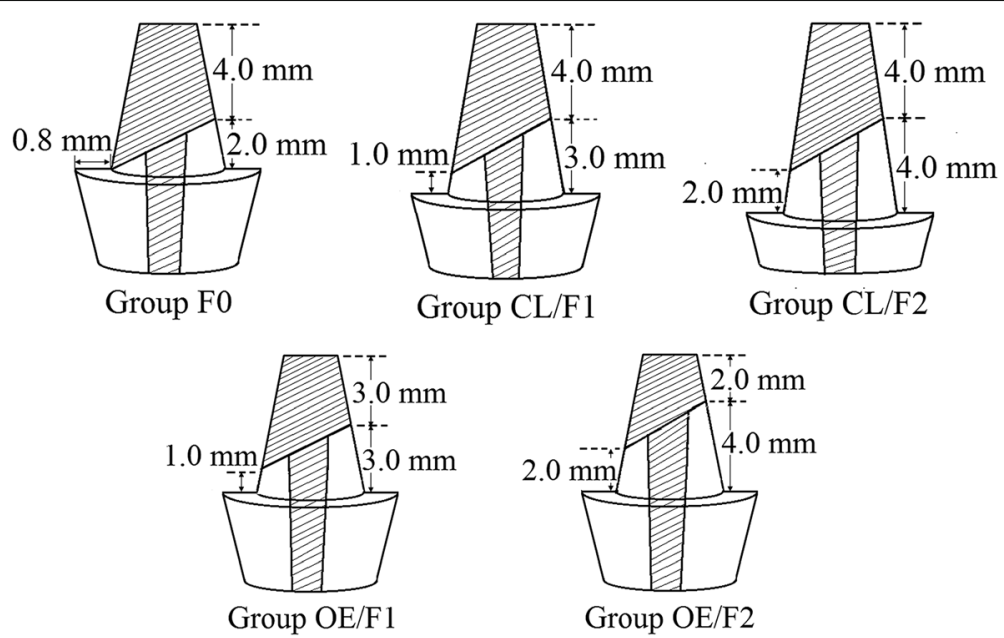

Fig. 2 Preparation designs. F0: with $0.0 \mathrm{~mm}$ buccal and $2.0 \mathrm{~mm}$ lingual ferrule lengths, as control; CL/F1: with simulated crown lengthening and $1.0 \mathrm{~mm}$ buccal and $3.0 \mathrm{~mm}$ lingual ferrule lengths; CL/F2: with simulated crown lengthening and $2.0 \mathrm{~mm}$ buccal and $4.0 \mathrm{~mm}$ lingual ferrule lengths; OE/F1: with simulated orthodontic forced tooth eruption and $1.0 \mathrm{~mm}$ buccal and $3.0 \mathrm{~mm}$ lingual ferrule lengths; OE/F2: with simulated orthodontic forced tooth eruption and $2.0 \mathrm{~mm}$ buccal and $4.0 \mathrm{~mm}$ lingual ferrule lengths

universal load-testing system (MTS810, MTS Systems Co., USA), with the frequency of $1.6 \mathrm{~Hz}$ [3]. The failed specimens were recorded and the failure site pattern noted.

\section{Fracture resistance testing}

A unidirectional static load was then applied to the buccal cusp of the Co-Cr alloy crown of the specimen that had passed fatigue testing without failure, with the same load-testing machine (MTS810, MTS Systems Co., USA)

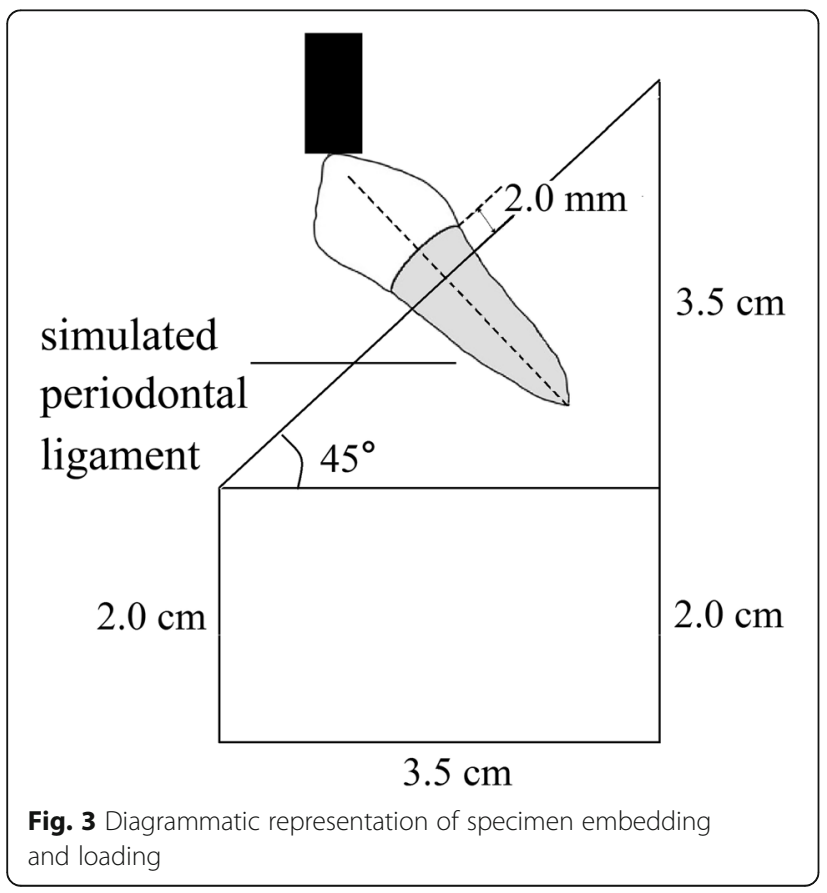

and the same load angle at a cross-speed of $0.5 \mathrm{~mm} / \mathrm{mi}$ nute (Fig. 3). The force (kilonewton, $\mathrm{kN}$ ) for initial root fracture was recorded and the failure pattern noted. The fracture modes were divided in repairable (less severe fractures located at or above the cervical third of the roots and potentially repairable) and irrepairable (catastrophic fractures, such as vertical or oblique root fracture located below the cervical third of the roots), according to the root fracture sites.

\section{Statistical analysis}

Statistical analysis was performed using SPSS 21.0 for Windows (SPSS Inc., Chicago, IL, USA). Two-way ANOVA with the Tukey HSD test and Fisher's exact test were used to detect any significant differences between the groups. The probability level for statistical significance was set at $\alpha=0.05$.

\section{Results}

No specimen failed during the fatigue resistance testing. The mean forces required to fracture the restored teeth and the specimen fracture patterns in each group are shown in Table 2. For fracture resistance, 2-way ANOVA revealed a statistically significant difference in the effect of ferrule length $(\mathrm{F}=4.955, P=0.012)$ but no significant differences in the effect of cervical treatment methods $(\mathrm{F}=0.152, P=0.699)$ or interactions between the two sources of variation $(\mathrm{F}=0.043, P=0.958)$ were discerned (Table 3).

For the simulated SCLM and OFEM, no significant differences were found in fracture resistance between groups $\mathrm{CL} / \mathrm{F} 1$ and $\mathrm{CL} / \mathrm{F} 2$ and between groups $\mathrm{OE} / \mathrm{F} 1$ and OE/F2 $(P>0.05)$. Only the fracture loads of group 
Table 2 Mean force $(\mathrm{kN})$ required to fracture the tooth roots and the root fracture sites, in each group

\begin{tabular}{|c|c|c|c|c|}
\hline \multirow[t]{2}{*}{ Groups } & \multirow{2}{*}{$\begin{array}{l}\text { Fatigue } \\
\text { testing }\end{array}$} & \multirow{2}{*}{$\begin{array}{l}\text { Fracture } \\
\text { strength }(\mathrm{kN})^{\mathrm{a}}\end{array}$} & \multicolumn{2}{|l|}{ Root fracture sites ${ }^{\mathrm{b}}$} \\
\hline & & & At or above cervical $1 / 3$ & Below cervical 1/3 \\
\hline$\overline{F O}$ & $0 / 8$ & $1.01(0.26)$ & 7 & 1 \\
\hline $\mathrm{CL} / \mathrm{F} 1$ & $0 / 8$ & $0.91(0.29)$ & 6 & 2 \\
\hline $\mathrm{CL} / \mathrm{F} 2$ & $0 / 8$ & $0.73(0.19)$ & 8 & 0 \\
\hline OE/F1 & $0 / 8$ & $0.96(0.25)$ & 6 & 2 \\
\hline $\mathrm{OE} / \mathrm{F} 2$ & $0 / 8$ & $0.76(0.20)$ & 7 & 1 \\
\hline
\end{tabular}

Group codes are defined in Table 1

${ }^{a}$ Mean (Standard Deviation)

${ }^{b}$ Failed roots were classified repairable (the fracture sites located at or above cervical one-third), and irrepairable (the fracture sites below cervical one-third)

CL/F2 were significantly lower than that of the control group (Group F0) $(P=0.036)$ (Table 4). The control group F0 had the highest fracture resistance, and the fracture loads of the obliquely-broken residual roots decreased along with the increasing ferrule lengths regardless of whether SCLM or OFEM had been used.

Almost all the fracture lines were found at or above the cervical one-third of the roots (Table 2). No statistically significant differences in fracture modes were found among the groups by Fisher's exact test $(P=1.00)$.

\section{Discussion}

\section{Specimen preparation and fracture strength testing}

Mandibular first premolars were selected for this study as these teeth were vulnerable to oblique root fracture because of wedge-shaped defect and following endodontic treatment [21]. The teeth were collected for orthodontic reasons from young adults who lived in the same area, and had very similar root forms and dimensions, as shown in Table 1. Gross destruction of coronal tooth structure was simulated by using standardized root-face preparations. The obliquely broken teeth may also need SCLM [16-18] or OFEM [19, 20], which facilitates placement of a long complete ferrule to potentially improve the fracture resistance of the residual roots $[3,5-$ 8]. All the cores and ferrule preparations were machined by the same person (Q-F M) using the same milling device, to decrease the personal error at a minimum.

The roots of the restored teeth were coated with silicone rubber and embedded in acrylic resin. The moduli of elasticity of these materials approximated those of the

Table 3 ANOVA table representing effective decomposition of main variables and their interaction

\begin{tabular}{llllll}
\hline Source & Sum of Squares & df & Mean Square & $F$ & $P$ \\
\hline Ferrule & 0.580 & 2 & 0.290 & 4.955 & $0.012^{\mathrm{a}}$ \\
Treatment method & 0.009 & 1 & 0.009 & 0.152 & 0.699 \\
Interaction & 0.005 & 2 & 0.003 & 0.043 & 0.958 \\
Error & 2.460 & 42 & 0.059 & & \\
\hline
\end{tabular}

${ }^{\mathrm{a}}$ Statistically significant viscoelastic periodontal ligament and the alveolar bone, respectively $[22,23]$. The in vitro dynamic loading testing and the following unidirectional static loading forces were both used in this and many other studies of teeth fractures, in order to closely simulate the complex oral mastication $[3,11]$. The oblique force applied at $135^{\circ}$ from the long axis of the mandibular premolar was employed to simulate functional working-side buccal cuspid loading [24].

\section{Fracture resistance of restored premolars}

The effective clinical crown length (Ce) to embedded root length $(\mathrm{Rb})$ ratio of the restored mandibular premolar with its root embedded in acrylic resin, is defined as "the physical relationship between the portion of the tooth not in the alveolar bone and the portion within the alveolar bone, as determined radiographically" [25]. When the oblique force applied to the buccal cuspid of the premolar, the tooth with its root embedded in the acrylic resin could be considered as a Class I lever, with the fulcrum in the cervical portion [26]. The fracture resistance of endodontically treated teeth is dependent on the level of surrounding supporting alveolar bone and the reduction of alveolar bone height may lead to an increased risk of tooth failure $[27,28]$. SCLM increases the effective clinical crown length of the lever (effort arm) during the cervical ferrule preparation, with the embedded root length (resistance arm) decreased. Thus, the $\mathrm{Ce} / \mathrm{Rb}$ ratio for groups $\mathrm{CL} / \mathrm{F} 1$ and CL/F2 in this study were 1.10 and 1.33 (20.9 and 46 . $2 \%$ greater than the control group F0), and the mean fracture resistance were 9.9 and $27.7 \%$ lower than that for the control group F0, respectively (Table 2 and Fig. 4). OFEM

Table 4 Statistical comparisons between groups using Tukey HSD tests

\begin{tabular}{lll}
\hline $\begin{array}{l}\text { Buccal Ferrule } \\
\text { length }\end{array}$ & $\begin{array}{l}\text { Simulated crown } \\
\text { lengthening }\end{array}$ & $\begin{array}{l}\text { Simulated forced } \\
\text { eruption }\end{array}$ \\
\hline $0.0 \mathrm{~mm} / 1.0 \mathrm{~mm}$ & $P=0.457$ & $P=0.712$ \\
$0.0 \mathrm{~mm} / 2.0 \mathrm{~mm}$ & $P=0.036^{\mathrm{a}}$ & $P=0.052$ \\
$1.0 \mathrm{~mm} / 2.0 \mathrm{~mm}$ & $P=0.154$ & $P=0.107$
\end{tabular}

${ }^{\mathrm{a}}$ Statistically significant 

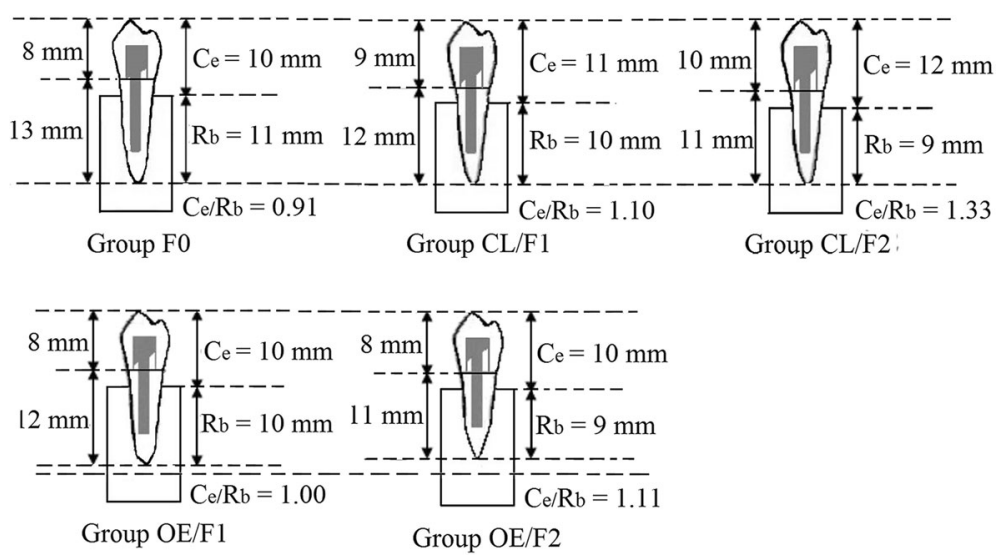

Fig. 4 Effective crown length (Ce) to root length in bone (Rb) ratios (Ce/Rb) for restored teeth: group codes are defined in Fig. 1

only decreases the embedded root length of the tooth, remaining the height of the crown portion the same as that in control group F0. However, with an increase in ferrule height prepared in the cervical portion and the reduction of root length embedded in bone, the diameter and dentine bulk of the residual root was decreased towards the root apex because of the root taper. Thus, the mean fracture resistance for group OE/F1 and OE/F2 were 5.0 and $24.8 \%$ lower than that for the control group, respectively (Table 2 ).

The crown-to-root ratio is one of the main variables in evaluating the suitability of a tooth as an abutment for a fixed partial denture $[4,29,30]$. Shillingburg suggested 1:1 as a minimum ratio for a prospective abutment under normal circumstances [30]. In this study, the crown-toroot ratio was defined as the effective clinical crown length $(\mathrm{Ce})$ to embedded root length $(\mathrm{Rb})$ ratio $(\mathrm{Ce} / \mathrm{Rb})$. As shown in Fig. 4, the $\mathrm{Ce} / \mathrm{Rb}$ ratio for the control group F0 was 0.91, which was less than the minimum suggested. In contrast, the $\mathrm{Ce} / \mathrm{Rb}$ ratios for groups $\mathrm{CL} / \mathrm{F} 1, \mathrm{CL} / \mathrm{F} 2$, $\mathrm{OE} / \mathrm{F} 1$ and $\mathrm{OE} / \mathrm{F} 2$ were $1.10,1.33,1.00$ and 1.11 respectively, all of which were equal to, or more than, 1:1 (the acceptable minimum ratio), which may be another reason for the variable trend of fracture resistance in this study (Table 2 and Fig. 4). The relationship between the crownto-root ratio and the fracture resistance of the endodontically treated teeth was also supported by other in vitro study [31], but further more researches being needed for in the future.

In this in vitro study, the combination of cervical treatment methods (SCLM or OFEM) and a complete ferrule preparation decreased the fracture resistance of endodontically-treated obliquely-fractured mandibular premolar. Therefore, the null hypothesis that the fracture resistance of endodontically treated residual roots would not be affected by the ferrule length, was rejected; however, that the fracture resistance would not be affected by the cervical treatment methods, was accepted.

\section{Conclusions}

Within the limitations of this in vitro study, the following conclusions were drawn:

1. The fracture resistance of endodontically treated premolar with a lingual-to-buccal oblique fracture and an incomplete ferrule preparation were highest.

2. The combination of cervical treatment methods (SCLM or OFEM) and a complete ferrule preparation decreased the fracture resistance of endodontically-treated mandibular premolar.

Abbreviations

$\mathrm{Ce} / \mathrm{Rb}$ : The effective clinical crown length (Ce) to embedded root length (Rb) ratio; CEJ: Cemento-enamel junction; kN: Kilonewton; OFEM: Orthodontic forced eruption method; SCLM: Surgical crown lengthening method

\section{Acknowledgements}

The authors thank Shanghai Dental Lab for their support with the milling machine and the State Key Laboratory of the China University of Mining and Technology for their support with the fracture test.

\section{Funding}

This research was supported by Jiangsu Provinicial medical youth talent (grant number QNRC-2016391). The authors declare that the funding body played no role in the design of the study and collection, analysis, and interpretation of data and in writing the manuscript.

\section{Availability of data and materials}

The data supporting the conclusions of this study is included within the article.

\section{Authors' contributions}

QF-M participated in the research design of the study, data analysis and wrote the manuscript. Q-M participated in the testing process and in the design of the study. TD-W participated in the research design and data analysis, and YM-C participated in the design of the study and reviewed the article. All authors read and approved the final manuscript.

\section{Ethics approval and consent to participate}

Ethics approval was obtained from the Ethics Committee of Affiliated Stomatology Hospital of Nanjing Medical University and written consent of the participants whose premolars were used in the study was given.

Competing interests

The authors declare that they have no competing interests. 


\section{Publisher's Note}

Springer Nature remains neutral with regard to jurisdictional claims in published maps and institutional affiliations.

\section{Author details}

'Department of Stomatology, Xuzhou Central Hospital, Xuzhou 221009, Jiangsu Province, China. ${ }^{2}$ College of Stomatology, Nanjing Medical University, 136 Hanzhong Road, Nanjing 210029, Jiangsu Province, China.

Received: 5 July 2017 Accepted: 1 May 2018

Published online: 10 May 2018

\section{References}

1. Yang A, Lamichhane A, Xu C. Remaining coronal dentin and risk of fiberreinforced composite post-core restoration failure: a meta-analysis. Int J Prosthodont. 2015;28:258-64

2. Santana FR, Castro CG, Simamoto-Júnior PC, Soares PV, Quagliatto PS, Estrela C, et al. Influence of post system and remaining coronal tooth tissue on biomechanical behavior of root filled molar teeth. Int Endod J. 2011;44:386-94

3. Zicari F, Van Meerbeek B, Scotti R, Naert I. Effect of ferrule and post placement on fracture resistance of endodontically treated teeth after fatigue loading. J Dent. 2013;41:207-15.

4. Mekayarajiananonth T, Chitcharus N, Winkler S, Bogert MC. The effect of fiber dowel heights in resin composite cores on restoration failures of endodontically treated teeth. J Oral Implantol. 2009;35:63-9.

5. Santos-Filho PC, Veríssimo C, Soares PV, Saltarelo RC, Soares CJ, Marcondes Martins LR. Influence of ferrule, post system, and length on biomechanical behavior of endodontically treated anterior teeth. J Endod. 2014;40:119-23.

6. Roscoe MG, Noritomi PY, Novais VR, Soares CJ. Influence of alveolar bone loss, post type, and ferrule presence on the biomechanical behavior of endodontically treated maxillary canines: strain measurement and stress distribution. J Prosthet Dent. 2013;110:116-26.

7. Juloski J, Radovic I, Goracci C, Vulicevic ZR, Ferrari M. Ferrule effect: a literature review. J Endod. 2012:38:11-9.

8. Meng QF, Chen LJ, Meng J, Chen YM, Smales RJ, Yip KH. Fracture resistance after simulated crown lengthening and forced tooth eruption of endodontically-treated teeth restored with a fiber post-and-core system. Am J Dent. 2009;22:147-50.

9. Naumann M, Preuss A, Rosentritt M. Effect of incomplete crown ferrules on load capacity of endodontically treated maxillary incisors restored with fiber posts, composite build-ups, and all-ceramic crowns: an in vitro evaluation after chewing simulation. Acta Odontol Scand. 2006:64:31-6.

10. Kutesa-Mutebi A, Osman YI. Effect of the ferrule on fracture resistance of teeth restored with prefabricated posts and composite cores. Afr Health Sci. 2004:4:131-5

11. Mangold JT, Kern M. Influence of glass-fiber posts on the fracture resistance and failure pattern of endodontically treated premolars with varying substance loss: an in vitro study. J Prosthet Dent. 2011;105:387-93.

12. Ferrari M, Vichi A, Fadda GM, Cagidiaco MC, Tay FR, Breschi L, et al. A randomized controlled trial of endodontically treated and restored premolars. J Dent Res. 2012;91(7 Suppl):72S-8S.

13. Hou QQ, Gao YM, Sun L. Effects of residual coronal walls on the fracture resistance under dynamic loading in fiber post-core and crown system. J Modem Stomatol. 2013;27:129-32.

14. Ng CC, Dumbrigue HB, Al-Bayat MI, Griggs JA, Wakefield CW. Influence of remaining coronal tooth structure location on the fracture resistance of restored endodontically treated anterior teeth. J Prosthet Dent. 2006;95:290-6.

15. Liu SM, Liu YH, Lu X, Xu YX, Xu J. Influence of incomplete ferrule on stress distribution of post and core restored maxillary premolar. Chin J Stomatol. 2012:47:162-6

16. Levine DF, Handelsman M, Rayon NA. Crown lengthening surgery: a restorative driven periodontal procedure. J Calif Dent Assoc. 1999;27:143-51.

17. de Oliveira PS, Chiarelli F, Rodrigues JA, Shibli JA, Zizzari VL, Piattelli A, et al. Aesthetic surgical crown lengthening procedure. Case Rep Dent. 2015;2015:437412

18. Parwani SR, Parwani RN. Surgical crown lengthening: a periodontal and restorative interdisciplinary approach. Gen Dent. 2014;62:e15-9.
19. Patil $P G$, Nimbalkar-Patil SP, Karandikar AB. Multidisciplinary treatment approach to restore deep horizontally fractured maxillary central incisor. J Contemp Dent Pract. 2014;15:112-5.

20. Rokn AR, Saffarpour A, Sadrimanesh R, Iranparvar K, Saffarpour A, Mahmoudzadeh $\mathrm{M}$, et al. Implant site development by orthodontic forced eruption of nontreatable teeth: a case report. Open Dent J. 2012;6:99-104.

21. Wu MK, van der Sluis LW, Wesselink PR. Comparison of mandibular premolars and canines with respect to their resistance to vertical root fracture. J Dent. 2004:32:265-8.

22. Watanabe MU, Anchieta RB, Rocha EP, Kina S, Almeida EO, Freitas AC Jr, Basting RT. Influence of crown ferrule heights and dowel material selection on the mechanical behavior of root-filled teeth: a finite element analysis. J Prosthodont. 2012;21:304-11.

23. Bourauel C, Freudenreich D, Vollmer D, Kobe D, Drescher D, Jäger A. Simulation of orthodontic tooth movements. A comparison of numerical models. J Orofac Orthop. 1999;60:136-51.

24. Sherfudhin H, Hobeich J, Carvalho CA, Aboushelib MN, Sadig W, Salameh Z. Effect of different ferrule designs on the fracture resistance and failure pattern of endodontically treated teeth restored with fiber posts and allceramic crowns. J Appl Oral Sci. 2011;19:28-33.

25. The glossary of prosthodontics terms. J Prosthet Dent. 1999:81:63.

26. Wilson TG, Kornman KS. Fundamentals of periodontics. 2nd ed. Chicago: Quintessence; 2003. p. 531-9.

27. Naumann M, Rosentritt M, Preuss A, Dietrich T. The effect of alveolar bone loss on the load capability of restored endodontically treated teeth: a comparative in vitro study. J Dent. 2006;34:790-5.

28. Luo Z, Zhang LL, Zhang Y, Liu YH, Xu J. Influence of alveolar bone heights on fracture resistance and pattern of post and core restored maxillary premolars. J Peking Univ (Health Sci). 2014;46:62-6.

29. Grossmann Y, Sadan A. The prosthodontic concept of crown-to-root ratio: a review of the literature. J Prosthet Dent. 2005;93:559-62.

30. Shillingburg HT, Sather DA, Wilson EL, CainJR MDL, Blanco LJ, Kessler JC. Fundamentals of fixed prosthodontics. 4th ed. Chicago: Quintessence; 2012. p. 99-130.

31. Meng $Q F$, Chen $L$, Meng J. In vitro study evaluating the effect of different subgingival root exposure methods and ferrule designs on fracture resistance of residual root. Hua Xi Kou Qiang Yi Xue Za Zhi. 2014:32:75-9.

\section{Ready to submit your research? Choose BMC and benefit from:}

- fast, convenient online submission

- thorough peer review by experienced researchers in your field

- rapid publication on acceptance

- support for research data, including large and complex data types

- gold Open Access which fosters wider collaboration and increased citations

- maximum visibility for your research: over $100 \mathrm{M}$ website views per year

At BMC, research is always in progress.

Learn more biomedcentral.com/submissions 